\title{
Lateral Amyotrophic Sclerosis and Intestinal Microbiota Transplantation
}

ISSN: 2637-7632

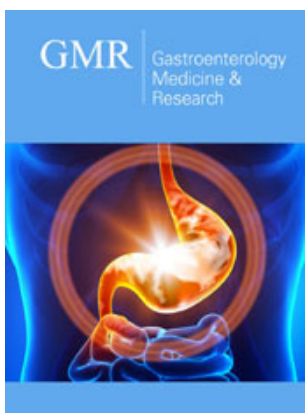

${ }^{* 1}$ Corresponding author: Álvaro Zamudio Tiburcio, Department of Gastroenterology, México

Submission: 制 April 24, 2019

Published: : May 30, 2019

Volume 3 - Issue 2

How to cite this article: Álvaro Z-T, Héctor B-R,Pedro A R-L. Lateral Amyotrophic Sclerosis and Intestinal Microbiota Transplantation. Gastro Med Res. 3(2). GMR.000558 2019.

DOI: 10.31031/GMR.2019.03.000558

Copyright@ Álvaro Zamudio Tiburcio,This article is distributed under the terms of the Creative Commons Attribution 4.0 International License, which permits unrestricted use and redistribution provided that the original author and source are credited.

\author{
Álvaro Zamudio-Tiburcio ${ }^{1 *}$, Héctor Bermúdez-Ruiz ${ }^{2}$ and Pedro Antonio Rey- \\ es-López ${ }^{3}$ \\ ${ }^{1}$ Department of Gastroenterology, México \\ ${ }^{2}$ Department of Endoscopy, México \\ ${ }^{3}$ Department of Cardiology, México
}

\section{Abstract}

Keywords: LAS: Lateral Amyotrophic Sclerosis; IMT: Intestinal Microbiota Transplantation; FMT: Fecal Microbiota Transplantation; MS: Multiple Sclerosis

\section{Summary}

Male, 47 years old. For 26 years, he has a lack of extension and elevation of the right thumb. It extended to the whole hand, carpus and forearm. When he was child a vehicle hit his head, at the right temporal level, he did not lose consciousness. He practiced Extreme Soccer 2-3 hours a day. From 10 to 15 years old. In 1987 spider bite on the right leg. He made black process, of 10 centimetres that it took to heal. In 1998, with the problem he worked at 4 thousand meters high. The disorder did not advance. In 2000, car accident. In 2004, diminution of the strength in the left ankle. One year later the right. He cannot stand on tiptoes. Contracture in the legs, as well as the right arm. Pain in cervical $7^{\text {th }}$, when bending over and incorporating the neck. Two Magnetic Resonances, with probable cervical hernia, small. Electromyography, normal. Genetic studies, No. HIV negative. Leukaemia of T lymphocytes in humans. Polio and West Nile virus not performed. Thereafter they treated him with ampules of Complex B, intramuscularly, daily and the process did not progress. Apitherapy once a week ( 60 bee stings), removing the sting. Lost weight on their forearms and ankles. It does pedal and cycling.

On physical examination, only lack of hyperextension in fingers of the right hand, as well as of the carpus on the same side. Standing tends to fall. He cannot stop spiking and get dizzy. The fingers of the right hand are hypotrophic. Frequent contractures in both legs. He has never taken medication. Regarding ELA, after 12 months of evolution Intestinal Microbiota Transplantation (IMT), comments on the following:

1. The evil progresses slowly especially in the legs, which is not bad, it could be worse, although ideally it should remain stable. The balance and strength of the front muscles of the thigh (above the knee) that support the weight when walking, is where progress is noticed.

2. The good thing is that I keep doing my activities in a more or less normal way (work, driving, dance, walk and bit clumsy. Ride a bicycle, Have sexual relationships). Of course, because of the ankles and legs I left football and other physical activities.

However, as an experience after the intervention, I can attest that my digestive system has worked better, my intestinal flora more resistant (less loose stomachs).

\section{Diagnostics}

1. Lateral Amyotrophic Sclerosis (LAS of right predominance)

2. Anxiety (30 Points, Hamilton scale)

3. Functional digestive disorder type IBS, variety, diarrhea 
4. Digestive functional disorder Gastrointestinal pain of centrally mediated disorders

5. Functional digestive disorder type Constipation type

6. Lactose intolerance

7. Over-weight Grade-II

8. Benign prostatic hypertrophy

9. Bilateral pterygium

$200 \mathrm{ml}$ of microbiota are applied in ascending colon, $100 \mathrm{ml}$. In transverse colon and $200 \mathrm{ml}$. In descending colon. Only spastic colon was found. We tried to pass the ileocecal valve, to deposit microbiota in terminal ileum and could not. Two days after the IMT, bowel movements normalized. There were burps that gave way spontaneously. Thirteen days later, abdominal pain decreased $75 \%$ and diarrhea was withdrawn. Anxiety decreased to 13 points on the Hamilton scale (17 points, less). The abdominal girth was 37.007 inches, decreased to 34.252. Regarding LAS, after 12 months of evolution, the patient comments on the following:

1. Prescribe for 3 months Rebiot I, ingestible solution. Take one a day.

2. Lactobacillus Paracasei/Vitamin B-6, Bifidobacterium lactis (BB-12), Vitamin B-12; BB-12; FOS fibre, Inulin.

\section{Discussion}

\section{Lateral Amniotrophic Sclerosis (LAS) Lou Gehrig's Disease}

It's a neurodegenerative process that affects motor neurons and other neuronal cells, causing severe disability and eventually death due to respiratory failure [1]. LAS affects approximately 1 in every 400 adults of Western European descent, which makes it the most common degenerative disease of the motor neuron network. From 85 to $90 \%$ of cases occur sporadically. In populations of European extraction, the most frequent cause is the repetition of the C9orf72 hexanucleotide expansion, C9orf72. Other genetic variants are also associated with earlier age at onset and faster progression; for example, the mutated SOD1 gene of the A4V variant [2].

Although its pathogenesis is not fully understood, it has been attributed to defects in RNA processing, as well as to the accumulation of protein aggregates in nerve cells and to defects in the intestinal microbiota.

There are no specific diagnostic tests, plus electromyography and genetic tests can support the diagnosis, [3] even though this remains clinical and is based on progressive painless weakness and dysfunction of the upper and lower motor neurons in the physical examination [4].

Although it does'nt refer precisely the LAS but to Multiple Sclerosis (MS). Borody [5-7] points out that: with respect to other possible treatable conditions, FMT tests are currently lacking. Isolated cases of FMT response include MS. And add. Infectious cause has been speculated in MS, although the potential of gastrointestinal pathogens to exert neurological effects remotely (as has been seen with many Clostridium species) has not been considered probable. Borody et al. [8] reports three wheelchair patients with MS treated with FMT for constipation. Intestinal symptoms resolved after FMT; however, in all cases, there was also progressive and dramatic improvement in neurological symptoms, with the three patients, recovering the ability to walk without help. Two of the patients with previous permanent urinary catheters underwent restoration of urinary function. In one of the three patients, the follow-up Magnetic Resonance, 15 years after the FMT, showed interruption of the progression of the disease and "no evidence of active disease".

People with MS have a different intestinal microbial community and increased translocation of low-grade bacteria from the intestines to the circulation. The observed change in intestinal bacteria in patients with MS regulates the immune functions involved in their pathogenesis $[9,10]$. Food has been considered the cause of the problem, as well as the intestinal microbiota, already mentioned [11,12]. Mirza et al, [13] point out that individuals with MS have distinct microbiota and, increased translocation of bacteria from the intestines to the low-grade circulation.

But what evidence exists to link the LAS with alterations of the Microbiota. We have the case of Wang [14] who comments that the gut microbiome has played a crucial role in the bidirectional axis of the brain and intestine that integrate the activities of the intestinal and central nervous system (CNS) and, therefore, the concept of the microbiome axis emerged -intestine-brain. The studies reveal how various forms of neuro-immune and neuro-psychiatric disorders are correlated or modulated with variations of microbiota products and antibiotics and exogenous probiotics.

And he concludes, the microbiome positions the peripheral immune homeostasis and predisposes the susceptibility of the host to autoimmune diseases of the CNS, such as Multiple Sclerosis. The neuronal, endocrine and metabolic mechanisms are also critical mediators of the microbiome-CNS signaling, which are more involved in neuro-psychiatric disorders such as autism, depression, anxiety, stress. But it's not only this author who ratifies the close relationship between Intestinal Microbiota and CNS. This relationship is also emphasized in other works [15-19]. IM has been related to different autoimmune diseases and there is evidence of its impact on neurodegenerative processes, research being directed towards which bacteria are the ones that produce these problems [20-24].

\section{Summary}

They review how dysbiosis contributes to symptomatology in autoimmune processes, including multiple sclerosis (MS) [25-28]. And so, we are facing numerous articles that abate the dysbiosis of the Intestinal Microbiota as the genesis of neurological alterations [29-32]. 


\section{Conclusion}

The IMT is beneficial in our patient and, other authors, as well as us describes success cases, we consider that it is a procedure that should not be disregarded [33-38]. The IMT is innocuous. Our patient presented burps, which yielded spontaneously. The LAS has not evolved in 6 months, although we must continue the follow-up, to set a definitive criterion. Most of the comorbidities subsided, which forces us to conclude that in addition to the primary neurological process, the IMT usually corrects most of the comorbidities, providing the patient with a higher quality of life. Bases and success stories appear in the literature, which concludes the importance of the IMT.

\section{References}

1. Mehta P, Kaye W, Bryan L, Larson, Copeland T, et al. (2016) Prevalence of amyotrophic lateral sclerosis-United States, 2012-2013. MMWR Surveill Summ 65(8): 1-12.

2. Armon C, Hardiman $O$ (2017) The beginning of precision medicine in ALS? Treatment to fit the genes. Neurology 89(18): 1850-1851.

3. Al-Chalabi A, Hardiman $O$ (2013) The epidemiology of ALS: A conspiracy of genes, environment and time. Nat Rev Neurol 9(11): 617-628.

4. van Eijk RPA, Jones AR, Sproviero W, Shatunov A, Shaw PJ, et al. (2017) Meta-analysis of pharmacogenetic interactions in amyotrophic lateral sclerosis clinical trials. Neurology 89(18): 1915-1922.

5. Oskarsson B, Horton DK, Mitsumoto H (2015) Potential environmental factors in amyotrophic lateral sclerosis. Neurol Clin 33(4): 877-888.

6. Adamczyk-Sowa M, Medrek A, Madej P, Michlicka W, Dobrakowski P (2017) Does the gut microbiota influence immunity and inflammation in multiple sclerosis pathophysiology? Journal of Immunology Research 2017:7904821.

7. Carabotti M, Scirocco A, Maselli MA, Severi C (2015) The gut-brain axis: interactions between enteric microbiota, central and enteric nervous systems. Annals of Gastroenterol 28(2): 203-209.

8. Borody TJ, Leis S, Campbell J, Torres M, Nowak A (2011) Fecal microbiota transplantation (FMT) in multiple sclerosis (MS). Am J Gastroenterol p. 942.

9. Borody TJ, Leis S, Campbell J (2011) Fecal microbiota transplantation (FMT) in multiple sclerosis (MS) [abstract]. Am J Gastroenterol 106: S352.

10. Daoud H, Valdmanis PN, Kabashi E, Dion P, Dupré N, et al. (2009) Contribution of TARDBP mutations to sporadic amyotrophic lateral sclerosis. ] Med Genet 46(2): 112-114.

11. Reijerkerk A, Lopez-Ramirez MA, van Het Hof B, Drexhage JA, Kamphuis WW, et al. (2013) MicroRNAs regulate human brain endothelial cell-barrier function in inflammation: Implications for multiple sclerosis. J Neurosci 33(16): 6857-6863.

12. von Geldern G, Mowry EM (2012) The influence of nutritional factors on the prognosis of multiple sclerosis. Nat Rev Neurol 8(12): 678-689.

13. Mirza A, Mao-Draayer Y (2017) The gut microbiome and microbial translocation in multiple sclerosis. Clinical Immunology 183: 213-224.

14. Wang Y, Kasper LH (2014) The role of microbiome in central nervous system disorders. Brain Behav Immun 38: 1-12.

15. Berer K, Krishnamoorthy G (2014) Microbial view of central nervous system autoimmunity. FEBS Lett 588(22): 4297-4213.
16. Cantarel BL, Waubant E, Chehoud C, Kuczynski J, DeSantis TZ, et al. (2015) Gut microbiota in multiple sclerosis: posible influence of inmmunomodulators. J Invest Med 63(5): 729-734.

17. Jhangi S, Gandhi R, Glanz B, Cook S, Nejad P, et al. (2014) Increased archaea species and changes with therapy in gut microbiome of multiple sclerosis subjects (S24.001). Neurology 82(10 Supplement).

18. Bhargava P, Mowry EM (2014) Gut microbiome and multiple sclerosis. Curr Neurology Neuroscience Rep 14(10): 492.

19. Tremlett H, Fadrosh DW, Faruqi AA, Zhu F, Hart J, et al. (2016) Gut microbiota in early pediatric multiple sclerosis: a case-control study. Eur J Neurol 23(8): 1308-1321

20. Mielcarz DW, Kasper LH (2015) The gut microbiome in multiple sclerosis. Cur Treat Options Neurol 17(4): 344.

21. Dopkins N, Nagarkatti PS, Nagarkatti M (2018) The role of gut microbiome and associated metabolome in the regulation of neuroinflammation in multiple sclerosis and its implications in attenuating chronic inflammation in other inflammatory and autoimmune disorders. Immunology 154(2): 178-185

22. Dionysios Antonopoulos A, Eugene Changa B (2016) Transplanting a microbial organ: The good, the bad, and the unknown. mBIO.

23. Cammarota G, Ianiro G, Tilg H, Rajilić-Stojanović M, Kump P, et al. (2017) European consensus conference on faecal microbiota transplantation in clinical practice. Gut 66(4): 569-580.

24. Sahi SK, Freedman SN, Mangalam AK (2017) Gut microbiome in multiple sclerosis: The players involved and the roles they play. Gut microbes 8(6): 607-651.

25. Berer K, Gerdes LA, Cekanaviciute E, Jia X, Xiao L, et al. (2017) Gut microbiota from multiple sclerosis patients enables spontaneous autoimmune encephalomyelitis in mice. Proc Natl Acad Sci U S A 114(40): 10719-10724.

26. Borre YE, O'Keeffe GW, Clarke G, Stanton C, Dinan TG, et al. (2014) Microbiota and neurodevelopmental windows: Implications for brain disorders. Trends Mol Med 20(9): 509-518.

27. Evrensel A, Ceylan, ME (2016) Fecal microbiota transplantation and its usage in neuropsychiatric disorders. Clinical Psychopharmacology and Neuroscience 14(3): 231-237.

28. Gupta A, Khanna S (2017) Fecal microbiota transplantation. JAMA 318(1): 102.

29. Makkawi S, Camara-Lemarroy C, Metz L (2018) Fecal microbiota transplantation associated with 10 years of stability in a patient with SPMS. Neurol Neuroimmunol Neuroinflamm 5(4): e459.

30. Hsiao EY, McBride SW, Hsien S, Sharon G, Hyde ER, et al. (2013) Microbiota modulate behavioral and physiological abnormalities associated with neurodevelopmental disorders. Cell 155(7): 1451-1463.

31. Benito-Leon J, Pisa D, Alonso R, Calleja P, Diaz-Sanchez M, et al. (2010) Associaton between multiple sclerosis and Candida species: evidence from a case-control study. Eur J Clin Microbiol Infect Dis 29(9): 11391145 .

32. Cekanaviciute E, Yoo BB, Runia TF, Debelius JW, Singh S, et al. (2017) Gut bacteria from multiple sclerosis patients modulate human $\mathrm{T}$ cells and exacerbate symptoms in mouse models. Proc Natl Acad Sci U S A 114(40): 10713-10718.

33. Rumah KR, Linden J, Fischetti VA, Vartanian T (2013) Isolation of Clostridium perfingens type $B$ in an individual at first clinical presentation of multiple sclerosis provides clues for environmental triggers of the disease. PLoS One 8(10): e76359. 
34. Álvaro Zamudio-Tiburcio, Héctor Bermudez Ruiz, Pedro Antonio ReyesLópez (2018) Successful Experience with an Intestinal Microbiota Transplantation. EC Microbiology 14(9): 666-670.

35. Kelly CR, Kunde SS, Khoruts A (2014) Guidance on preparing an investigational new drug application for fecal microbiota transplantation studies. Clin Gastroenterol Hepatol 12(2): 283-288.

36. Choi HH, Cho YS (2016) Fecal Microbiota transplantation: current applications, effectiveness, and future perspectives. Clin Endosc 49(3): 257265.
37. Budhram A, Parnathy S, Kremenchutzky M, Silverman M (2017) Breaking down the gut microbiome composition in multiple sclerosis. Multiple Sclerosis Journal 23(5): 628-636.

38. Castillo-Álvarez F, Marzo-Sola ME (2015) Role of the gut microbiota in the development of multiple sclerosis. Neurology 32(3): 175-184.

For possible submissions Click below: 